\title{
THE GROSS ANATOMY OF THE PERI-ARTICULAR TISSUES OF THE SHOULDER JOINT
}

\author{
BY \\ W. J. H. NAUTA and J. M. F. LANDSMEER \\ Department of Anatomy and Embryology, State University, Leiden, Netherlands
}

Since it has become evident that the pathological changes underlying disorders of the shoulder mechanism are not, in a number of cases, localized in one of the major joints of this region (scapulohumeral and acromio-clavicular joints), but, instead, in the tissues surrounding these joints, the need for a thorough knowledge of the anatomy of this tissue has imposed itself on all those who have to deal with such disorders. In the current textbooks of anatomy, however, little attention has been paid to the structures surrounding the shoulder joints. Although more or less adequate accounts of the matter are found in Rouvière's (1945) and in Frohse and Fraenkel's (1908) textbooks, and in some special papers dealing with the subject (Henke, 1874; Pfuhl, 1934; Kahlmeter, 1941) the distribution of these works has, perhaps, not been sufficiently wide to provide for a satisfactory introduction of the pertinent facts into clinical medicine. It is for this reason that we submit the present accountwhich is based partly on the foregoing papers and partly on our own observations on a large amount of dissecting-room material-to those clinicians who will be most interested in the anatomical basis of shoulder movements.

\section{Anatomical Description}

A glance at a suitable illustration in an atlas of anatomy will immediately disclose the important fact that the glenoid fossa of the scapula is overhung on the cranial side by an osteofibrous arch, the socalled fornix humeri, which is formed by (from before backwards) the coracoid process, the coracoacromial ligament, and the acromion (Fig. 1a). The fornix humeri bridges the lateral exit of the supraspinous fossa (Fig. 4). The space between this arch and the glenoid fossa is largest dorsally, that is, under the acromion. A large part of this space is occupied by the tendon of the supraspinatus muscle (Fig. 1b).
The capsule of the shoulder joint is largely enveloped by the tendons of the muscles which surround the joint. The subscapularis, supraspinatus, infraspinatus, and teres minor tendons all join in the formation of what Poirier (1904) has aptly termed a musculo-tendinous cuff (coiffe musculo-tendineuse), surrounding and, to a variable extent, blending with the joint capsule. On the cranial side the cuff is completed by the coracohumeral ligament, which bridges the gap between the supraspinatus and subscapularis tendons (Fig. 1b). Between the subscapular tendon and the coraco-humeral ligament there is a slit-like orifice (the oval foramen of Weitbrecht) which allows the bursa subscapularis to anastomose with the joint.

It is especially the cranial part of the musculotendinous cuff that demands our attention, since this part, which is formed by the supraspinatus tendon and the ventrally adjacent coraco-humeral ligament, is separated from the undersurface of the fornix humeri virtually only by space. During abductory movements in the shoulder joint the supraspinatus muscle withdraws its tendon through the narrow tunnel under the fornix humeri. At the final stage of the movement, however, the tendon is raised by its apophysis (the greater tubercle) to such an extent that its lateral part impinges on the acromion and the coraco-acromial ligament. Further abduction in the joint is checked by this occurrence, but it seems certain that some additional abduction is rendered possible by an outward rotation of the humerus, which moves the tendon and its apophysis backwards into a position underneath the acromion, where more space is available. In view of the everreturning conflict between the upper part of the musculo-tendinous cuff on the one hand and the fornix humeri on the other, it is not surprising that a bursa has developed in the narrow space between the two. This bursa is usually designated the subdeltoid bursa, but because this name is liable to 


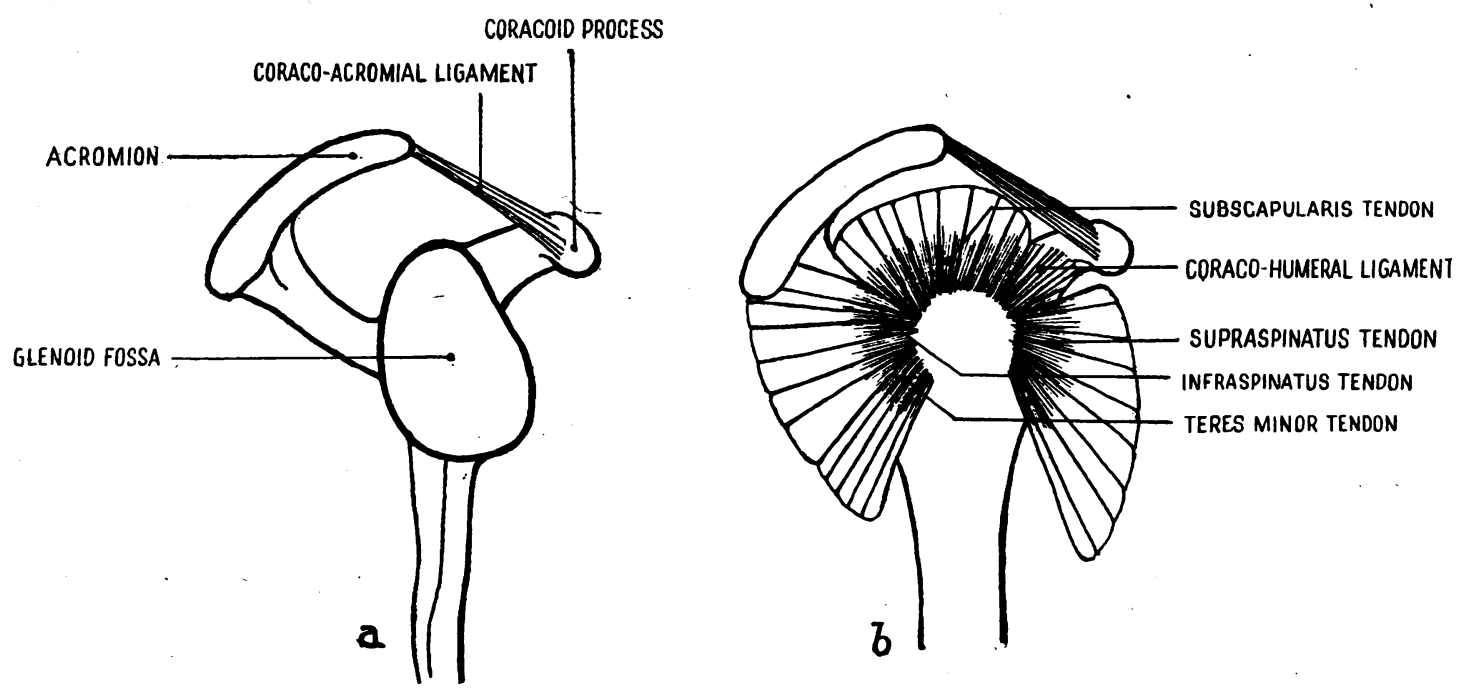

FIG. 1.-Schematic drawings of lateral aspects of: (a) fornix humeri, and (b) musculo-tendinous cuff of the shoulder joint. (b) has been redrawn and amplified from McGregor (1943).

cause confusion (see below) it will be referred to in the following as "subacromial bursa" (Fig. 3). To facilitate an understanding of its topography it will be necessary to deal with the fascial relations of the shoulder region.

Fascial Relations of the Shoulder Region.-On the medial side the coraco-acromial ligament (which covers the lateral exit of the supraspinous fossa) is continuous with the much thinner supraspinous fascia. Laterally, it continues into the important subdeltoid fascia, a connective-tissue sheet of considerable strength stretched out over the greater tubercle and the surgical neck of the humerus (Fig. $2,4,6)$. Dorsally, the subdeltoid fascia continues into the infraspinous fascia, a strong fascia covering the infraspinous and teres minor muscles, and ventrally it passes over into the subscapular fascia which covers the subscapularis muscle. The subdeltoid fascia can thus be regarded as the result of a junction of the several fasciae covering the muscles which take part in the formation of the musculotendinous cuff (that is, the fasciae subscapularis, supraspinata, and infraspinata). Distally, a small distance above the insertion of the deltoid muscle, the subdeltoid fascia blends with the periosteum of the surgical neck and is thus attached to the humerus.

Subdeltoid Fascia.-It will be clear from the foregoing description that the subdeltoid fascia is part of a vast sheet of connective tissue which envelops the whole complex formed by the upper part of the humerus, the shoulder joint, with its musculotendinous cuff, and the muscles contributing to this cuff (Fig. 2). On the scapular side this sheet is divided into three divisions - the subscapular, supraspinous, and infraspinous fasciae-by the bony rims separating the scapular fossae of the same names; on the lateral surface of the upper part of the humerus the three divisions unite to form the subdeltoid fascia, which has a skeletal attachment to the surgical neck of the humerus. It will be noticed that the fornix humeri is a strongly reinforced strip of that part of the connective-tissue sheet under consideration which covers the superior part of the musculo-tendinous cuff (supraspinatus tendon and coraco-humeral ligament).

A further point of interest is the relation between the subdeltoid fascia and the short head of the biceps. The tendon of this muscle is sometimes found to possess a broad lateral expansion blending with an aponeurotic subdeltoid fascia (Fig. 6). Although in the majority of cases this connexion is less strongly developed, a fibrous attachment of the lateral margin of the caput breve tendon to the subdeltoid fascia is a constant finding (Fig. 2b). It seems probable that the fascia can thus be made taut by the caput breve of the biceps.

On its ventral side the subdeltoid fascia is joined by the fascia coraco-clavi-pectoralis (costo-coracoid membrane). A superficial part of this fascia, after having covered the pectoralis minor muscle, extends laterally over the conjoined tendons of the caput breve of the biceps and the coraco-brachialis muscles and immediately afterwards comes to cover the subdeltoid fascia. After it has run freely over this fascia for a short distance the two fasciae blend 

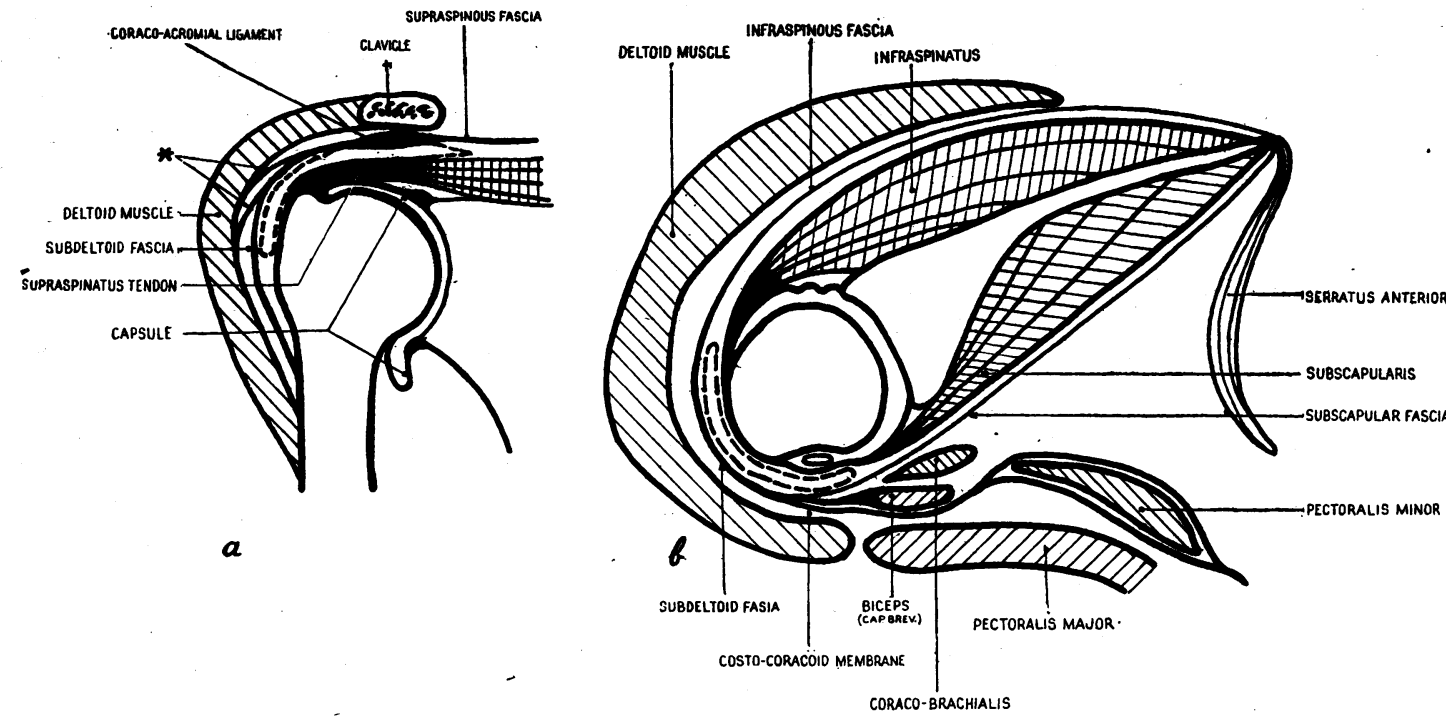

Fig. 2. Schematic sections through the shoulder joint $(a)$ in the frontal and $(b)$ in the horizontal plane. The subacromial bursa is indicated by broken lines.

In (a) notice that the subdeltoid fascia is a lateral extension of the coraco-acromial ligament (the supraspinous fascia being the medial continuation of this ligament). Notice also that the coraco-acromial ligament and the supraspinatus tendon are incorporated in the wall of the bursa. The small bundles of the deltoid muscle attaching to the subdeltoid fascia are marked by an asterisk.

(b) shows the continuation of the subdeltoid fascia into the subscapular and infraspinous fasciae. Notice the relation of the subdeltoid fascia to the tendon of the caput breve $\mathrm{m}$. bicipitis and to the costocoracoid membrane (compare with Fig. 6).

along an approximately vertical line (Fig. $2 b$; in Fig. 6 the fascia has been rolled up to this line).

The Subacromial Bursa. - The subdeltoid fascia is covered by the deltoid muscle, with which it is connected by a loose, felt-like connective tissue. We have been unable to find a bursa in this tissue in any of our preparations. For this reason we have followed Frohse and Fraenkel (1908) in omitting the name subdeltoid bursa for. what is more properly called the subacromial bursa. It is of importance to note that a rather variable number of small bundles of the deltoid muscle, originating from the tuberositas deltoidea of the humerus, is constantly found attached to the upper part of the subdeltoid fascia in a proximal direction (Fig. 2a). Presumably these bundles exert a distal pull on the fascia during abduction of the arm, and they may thus prevent the formation of folds in the fascia which would be liable to be incarcerated between the supraspinatus tendon and the fornix humeri.

Proximal to the distal attachment of the subdeltoid fascia to the periosteum of the humerus, a layer of extremely loose tissue is woven between the subdeltoid fascia and the surgical neck of the humerus. More proximally, just over the supraspinatus tendon, the subdeltoid fascia is separated from this tendon by the subacromial bursa (see below). It may be inferred from this fact-and manipulation of the upper arm in the cadaver shows the inference to be correct-that every movement of the upper arm in the shoulder joint is accompanied by a displacement of the upper part of the humerus with the musculo-tendinous cuff against the inside of the fibrous sheath encapsulating these structures. Since the fornix humeri forms a rigid and fixed part of this sheath the displacement relative to the sheath is greatest at this point.

It is, therefore, not surprising that the subacromial bursa is constantly found to occupy the narrow space under the fornix humeri, separating the latter from the upper part of the musculo-tendinous cuff (the supraspinatus tendon and the coraco-humeral ligament). Friction, however, is exerted not only by the musculo-tendinous cuff but also by the outer surface of the greater tubercle, and it is exerted not only against the under surface of the fornix humeri but also against the inner side of the sub-deltoid fascia (the latter of these two points will be understood if one realizes that, as mentioned in the previous account, the subdeltoid fascia is kept extended during abduction by part of the bundles of the deltoid muscle (Fig. 2a) ). This explains the 


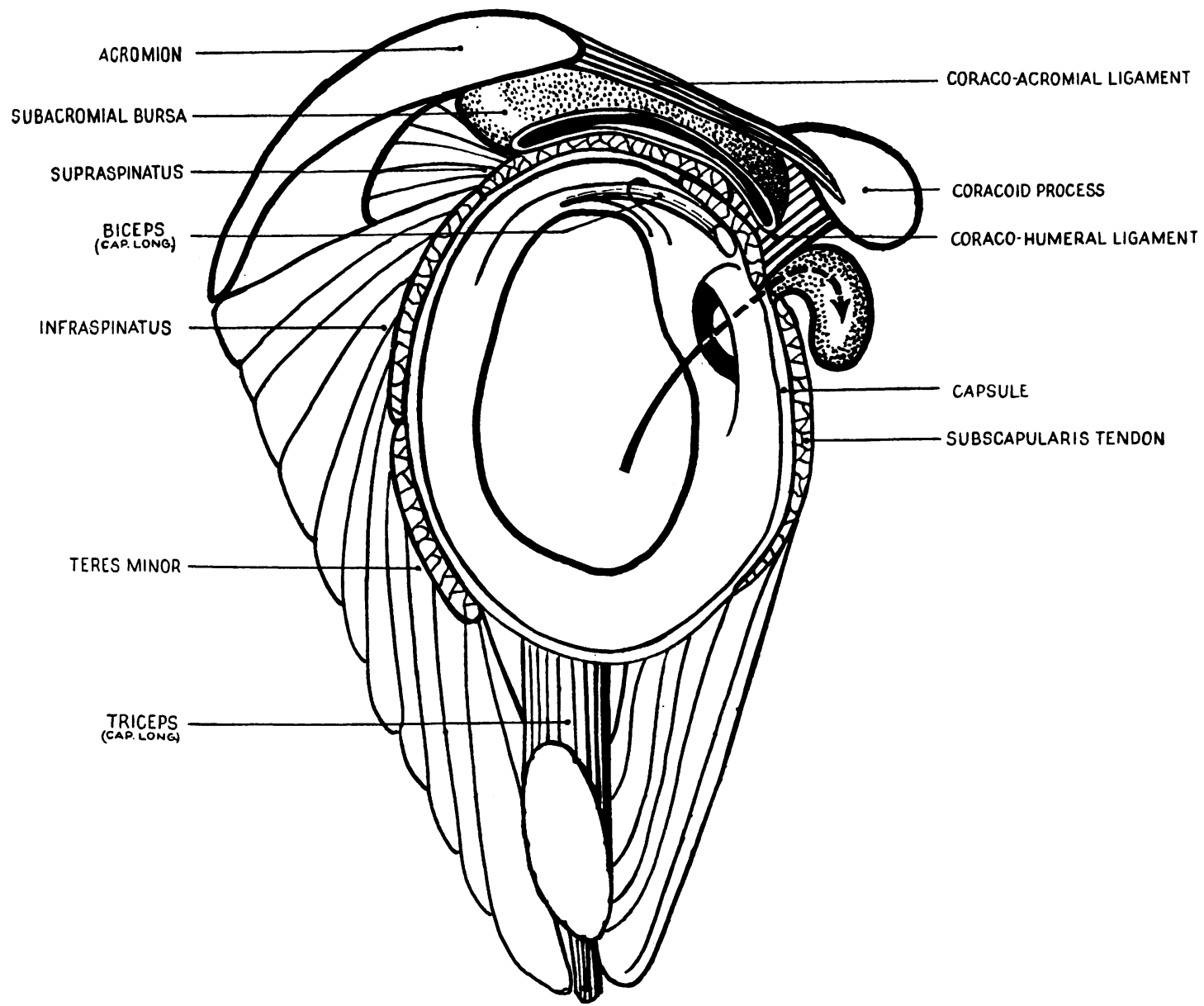

FIG. 3.-Semidiagrammatic drawing of the lateral aspect of the shoulder joint and its surroundings after exarticulation of the humerus. Notice that the capsule is in large part surrounded by the musculotendinous cuff, components of which are labelled. The coraco-humeral ligament radiates into the capsule. The subacromial bursa is situated between the upper part of the cuff and the fornix humeri. The subdeltoid fascia, which covers the bursa, has been removed. The arrow points through a foramen into the subcoracoid bursa.

fact that the bursa is constantly found to extend laterally beyond the insertion of the supraspinatus muscle over the outer surface of the greater tubercle and under cover of the subdeltoid fascia. Since this lateral extension necessarily follows the downward slope of the tuberosity, this is the deepest part of the subacromial bursa, and corpuscular substances are liable to collect here. The degree of lateral extension is, however, subject to important individual variation. A remarkably small lateral extension, for instance, is shown in Fig. 4; and Fig. 5 shows a subacromial bursa which reaches distally far over the lateral surface of the great tuberosity. When the arm is kept hanging down to the side of the body the opposite (medial or proximal) margin of the bursa rarely extends for more than a small distance medially beyond the medial border of the coraco-acromial ligament. This small part of the bursa is covered by the supraspinous fascia (Fig. 2a). Dorsally, the bursa constantly extends for some distance underneath the acromion. To the ventral side the bursa does not, as a rule, extend farther than the base of the coracoid process, but Pfuhl (1934) whose paper gives a good impression of the variability of the bursa subacromialis, records several instances of larger ventral extension (recessus subcoracoideus) of the bursa.

With respect to the relation of the subacromial bursa to its surrounding tissues the following facts are of importance. As a rule, the bursa can easily 


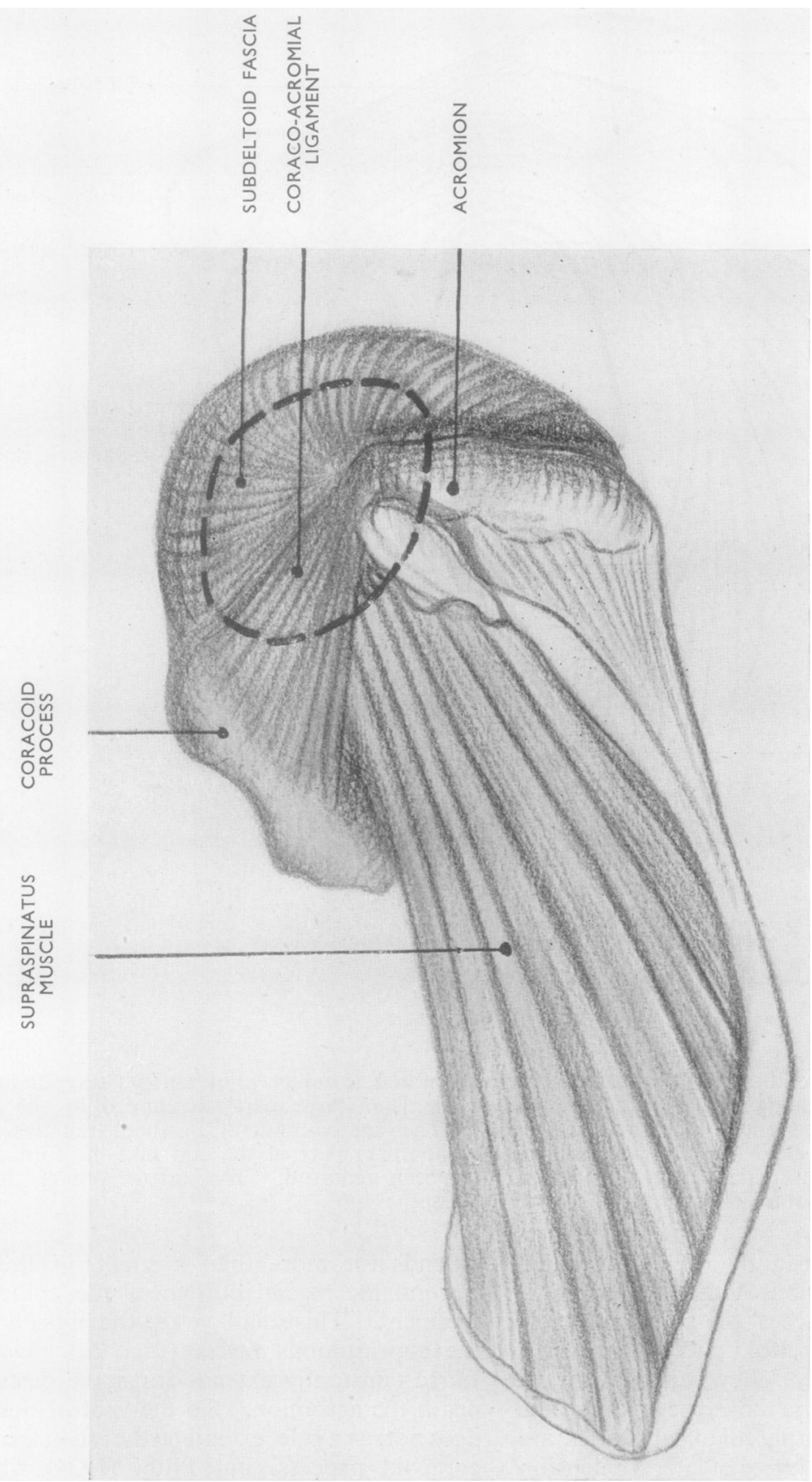

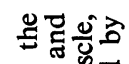

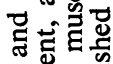
s. 를 政. E.⿱一兀) 䠉

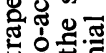
7 近 ส 80 궁

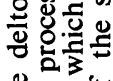
․․ㅇ. 记 ब递骂 ․ㅗㅇ.

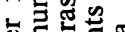

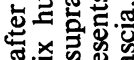

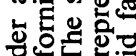
홍 क 茄

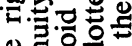

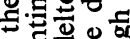
ธ。 进焉娄 卷. 要之管 空. 广 它 


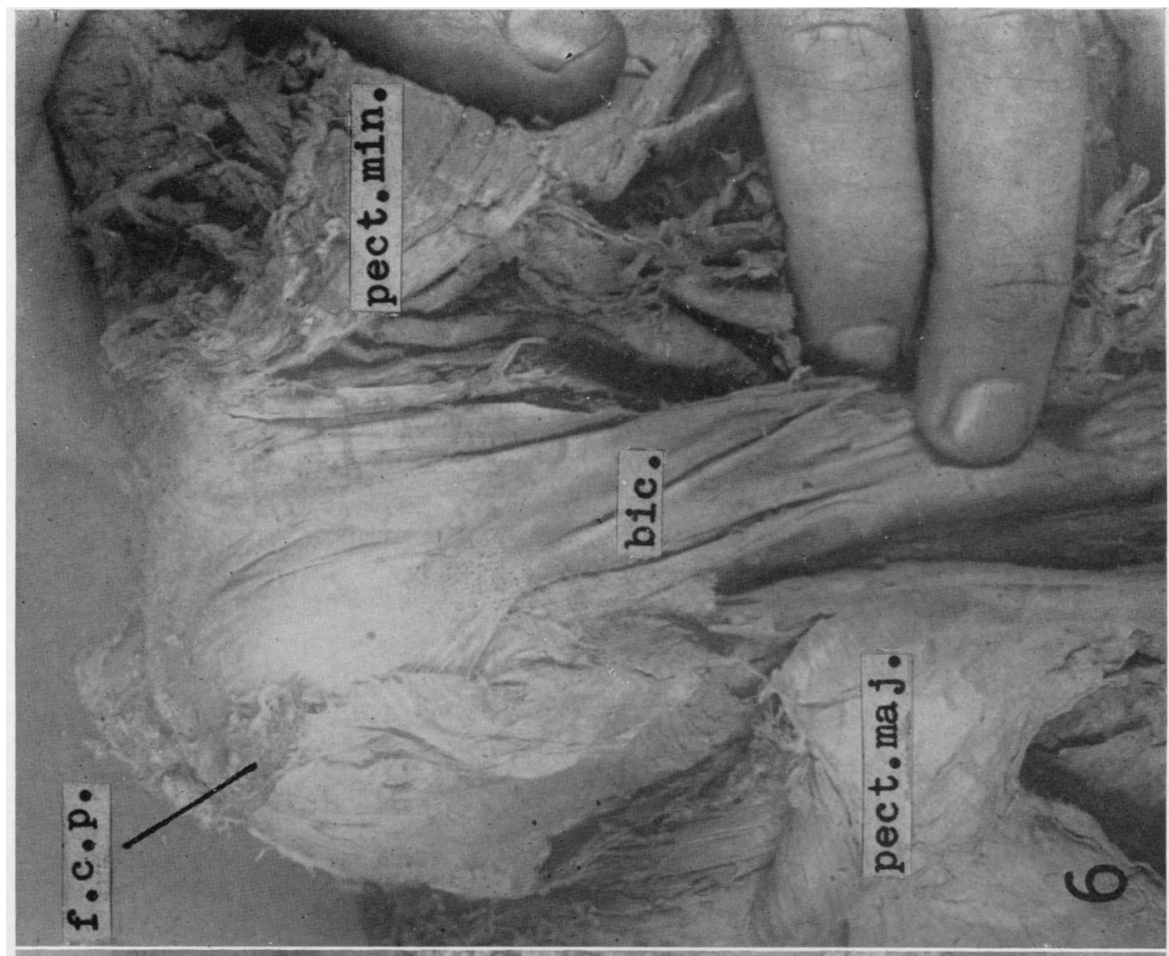

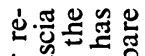
过论 可. 氙

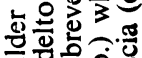

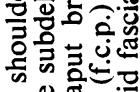
동 象

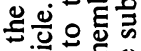

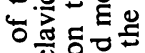
政. 边㐘卷 记 西

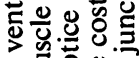

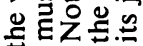
등흥영요 훙행ㅎㅀ

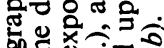

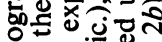

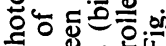
काष !) 它

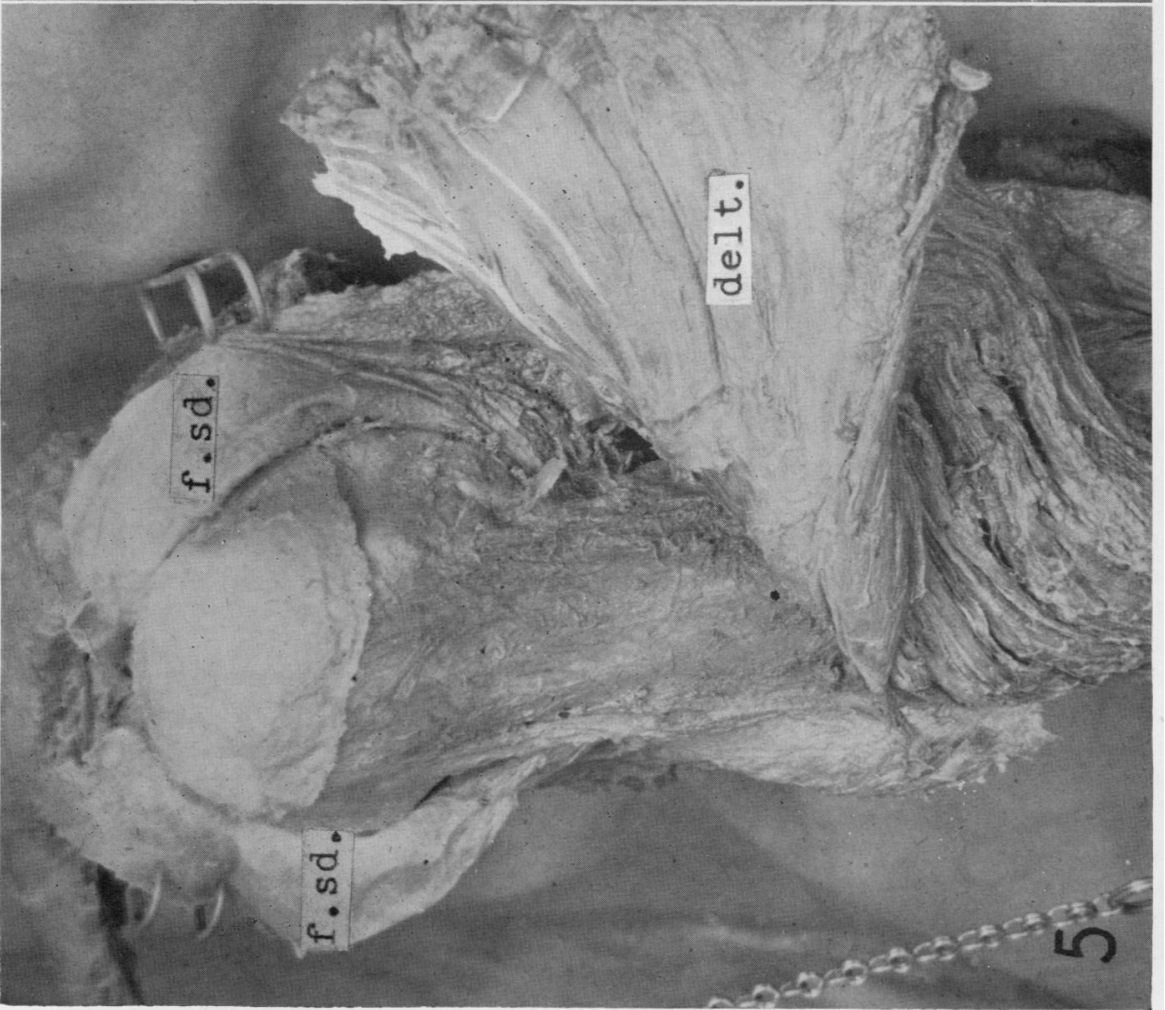

列 
be exposed by removing the subdeltoid fascia, which is rather loosely attached to the outer bursal wall (Fig. 5). In a number of our preparations, however, the subdeltoid fascia consisted of several layers, and in such cases it was difficult to identify the wall of the bursa. Quite a different relation exists between the bursa and the fornix humeri. The coraco-acromial ligament cannot be removed from the subjacent bursa without causing damage to the latter's outer wall. The acromion has a similar relation to the bursa. Like the adjacent part of the coracoacromial ligament its under-surface is incorporated in the outer wall of the bursa. The remainder of the coracc-acromial ligament (the part connected with the coracoid process) may lie free over the bursa, but it often also forms part of the outer wall of the latter. The relations of the inner wall of the subacromial bursa are as follows. This wall so strongly adheres to the underlying supraspinatus tendon that it is possible to say that the tendon forms part of the inner wall of the bursa. Where the bursa covers the greater tubercle it can easily be lifted from the latter by blunt dissection.

The strong adherence of the bursa to the supraspinatus tendon will cause the inner wall of the former to be displaced with every movement of the latter. During abduction, for instance, the inner wall of the bursa will be drawn medially with the supraspinatus tendon. The position of the outer wall of the bursa is certainly less dependent on the position of the humerus in the shoulder joint, since part of it is formed by the completely fixed fornix humeri, while the remainder of the outer wall is in large part related to the subdeltoid fascia, which during abduction is kept taut by small bundles of the deltoid muscle. The medial displacement of the inner wall of the bursa during abduction will imply a medial shift of its distal line of reflexion, and this shift is presumably facilitated by the loose attachment of the outer wall of the bursa to the subdeltoid fascia.

\section{Discussion}

It is of great interest to note that Pfuhl (1934) has demonstrated the presence of a layer of cartilaginous tissue covering that part of the undersurface of the acromion which stands in direct relation to the cavity of the subacromial bursa. On the basis of this finding Pfuhl has advocated the conception that the subacromial bursa should be regarded as a true joint between the fornix humeri and the musculotendinous cuff. The shoulder joint as a functional entity would thus be composed of a scapulo-humeral "Hauptgelenk" and a subacromial "Nebengelenk". The intervening part of the musculotendinous cuff, which is formed by the supraspinatus tendon and the coraco-humeral ligament, is regarded by Pfuhl as an intra-articular disc. It is a well known fact (see, for instance, McGregor, 1943) that rupture of the supraspinatus tendon may establish a communication of the shoulder joint with the subacromial bursa. It seems that such ruptures usually result from acute overaction of the supraspinatus muscle, but Pfuhl (1934) has observed large perforations of the tendon accompanying severe arthritis deformans of the shoulder joint, so that it would not seem impossible that some cases of rupture of the supraspinatus tendon are caused by repeated trauma of the tendon against the rough articular surface of the humeral head.

There is, indeed, sufficient reason to regard the subacromial bursa as a true joint rather than as an equivalent to the numerous other bursae which assist in the proper functioning of the apparatus of motion. Apart from Pfuhl's argument that a small part of the wall of the bursa is formed by cartilaginous tissue, the following other facts can be advanced in favour of this conception: (1) the subacromial bursa is the only bursa which is known to be able to reduce friction between two skeletal elements (greater tubercle of the humerus versus under surface of the acromion), and (2) the bursa is covered by and attached to a strong aponeurotic fascia, the subdeltoid fascia, which is kept extended during movements by some bundles of the deltoid muscle and by the short head of the biceps. Comparable mechanisms serving to prevent the formation of incarcerated folds in the capsule are formed in many other joints (capsule stretchers).

Although it would thus seem justified to speak of a subacromial joint, it is evident that the joint is an exceptional one functionally and morphologically. With regard to its function, it should be realized that its prime significance lies in the fact that it reduces the conflict which is bound to arise between an exceptionally mobile joint like the shoulder joint and the rigid tissues surrounding this joint. Morphologically it differs from most other joints in that only a very small part of its wall consists of cartilage and that it is largely a synovial sac with, of course, merely a virtual cavity. It follows that a slight proliferation of the wall of the subacromial joint in the course of an inflammatory process may suffice to result in partial or complete obliteration of the joint cavity with consequent anchorage of the musculo-tendinous cuff of the shoulder joint to the completely rigid fornix humeri, a condition which will greatly decrease the range of movements of the upper extremity.

\section{Summary}

The interest of clinical rheumatology for the periarticular tissues of the shoulder joint, together 
with the fact that current textbooks of anatomy fail to give satisfactory descriptions of these tissues, has led the authors to investigate this region anew. The following account is based on dissecting-room material.

A description has been given of the capsule of the shoulder joint and its relation to the fornix humeri (coraco-acromial ligament and acromion). The fornix humeri is part of a much larger fibrous system, the subdeltoid fascia. This fascia anteriorly fuses with the subscapularis fascia, posteriorly with the infraspinous fascia, and laterally to the periosteum of the surgical neck of the humerus. Tendon-fibres of the short head of the biceps fan out into this fascial sheet, whereas muscular fibres of the deltoid muscle insert into it in the distoproximal direction. Both may serve to stretch this fascial sheet during movements of the shoulder, thus preventing it from becoming enfolded under the fornix humeri. Between the capsule of the shoulder-joint on the one hand, and the fornix humeri and its lateral extension (the subdeltoid fascia) on the other, a bursa has developed-the subacromial bursa. A description has been given of the relation of this bursa to the surrounding tissues. A suggestion is made as to the rôle of the subdeltoid fascia and subacromial bursa in movements of the shoulder.

The authors wish to thank Mr. E. Bollee, Department of Anatomy, Leiden, for the accompanying photographs, and Mr. E. Brändli, Institute of Anatomy, Zürich, for the drawings which illustrate this paper. They are also indebted to Dr. J. J. Siemelink, Utrecht, for valuable criticism during the preparation of the paper.

\section{REFERENCES}

Frohse, F. and Fraenkel, M. (1908). “ "Die Muskeln des menschlichen Armes." In " Handbuch der Anatomie des Menschen." K. von Bardeleben. II, 2, 2. Gena.
Henke, K. (1874). “Ein Beitrag zur Pathologie des Schultergelenke." Inaug. diss. Marburg.

Kahlmeter, G. (1941). $\quad Z$. Rheumaforsch., 4, 251.

McGregor, A. Lee. (1943). "Synopsis of Surgical Anatomy." Bristol.

Pfuhl, W. (1934). Morph. Jahrb., 73, 300.

Poirier, P. (1904). "Traité d'Anatomie Humaine." Paris. Battaille et Cie.

Rouvière H. (1945). “ Anatomie Humaine, descriptive et topographique." Paris. Masson et Cie.

\section{L'Anatomie Macroscopique des Tissus Périarticulaires de l'Epaule}

\section{RÉSUMÉ}

L'intérêt du problème de la périarthrite huméroscapulaire, spécialement dans un sens rhumatologique, a conduit les auteurs à une recherche anatomique nouvelle sur la région scapulaire. La capsule de l'articulation huméro-scapulaire et ses relations à l'égard du fornix huméri sont décrites. Le fornix huméri (ligament coraco-acromial et acromion) fait part d'un système aponévrotique plus étendu, c'est à dire, l'aponévrose sous-deltoidienne. Cet aponévrose se confond antérieurement avec l'aponévrose sous-scapulaire, postérieurement avec l'aponévrose du sous-épineux, latéralement avec le périosteum du col chirurgical de l'humérus. Des fibres tendineuses de la courte portion du biceps se diversent dans l'aponévrose sous-deltoidienne, tandis que des faisceaux musculaires s'attachent sur celle-ci dans une direction disto-proximale. Il est bien sûr que les deux radiations font un dispositif d'un appareil de tension pour l'aponévrose pendant les mouvements de l'épaule. Entre la capsule de l'articulation huméroscapulaire et le fornix huméri et son extension latérale se trouve une bourse séreuse, c'est à dire, la bourse sous-acromiale. Les auteurs donnent une description de cette bourse et de ses relations à l'égard du revêtement aponévrotique de l'épaule. L'attention est fixée sur l'intérêt de la fonction de la bourse sous-acromiale et de l'aponévrose sousdeltoidienne pour les mouvements l'épaule. 